\title{
The Relationship between Sensory Processing Abilities and Gross and Fine Motor Capabilities of Children with Cerebral Palsy
}

\author{
Myoung-Ok Park ${ }^{\dagger}$
}

Dept. of Occupational Therapy, Division of Health Science, Baekseok University

Received: March 1, 2017 / Revised: March 19, 2017 / Accepted: April 6, 2017

(c) 2017 J Korean Soc Phys Med

\section{| Abstract |}

PURPOSE: The purpose of this study was to investigate the difference and relationship between sensory processing abilities, gross motor and fine motor capabilities in children with cerebral palsy.

METHODS: 104 children with cerebral palsy participated in the study. Sensory processing abilities of the subjects were measured by Short Sensory Profile (SSP). Gross and fine motor abilities were each measured using the Gross Motor Function Classification System (GMFCS) and Manual Ability Classification System (MACS), respectively.

RESULTS: There were significant correlations between SSP level and GMFCS $(\mathrm{R}=.72, \mathrm{p}<.00)$ or MACS $(\mathrm{R}=.77$, $\mathrm{p}<.00)$ levels. Significant differences were showed each gross motor $(p=.01)$ and fine motor level $(p=.00)$ among sensory processing level of children. In addition, sub-items of sensory processing as Tactile sensitivity, Movement sensitivity, Auditory filtering and Low energy/Weak were significantly were showed significant correlations gross motor and fine motor level $(\mathrm{p}=.01)$. Also, multiple regression result was

†Corresponding Author : parkmo@bu.ac.kr

This is an Open Access article distributed under the terms of the Creative Commons Attribution Non-Commercial License (http://creativecommons.org/licenses/by-nc/3.0) which permits unrestricted non-commercial use, distribution, and reproduction in any medium, provided the original work is properly cited. showed that as MACS level and GMFCS level were higher, the SSP total score was higher all of participants (adjusted $\left.\mathrm{R}^{2}=.62\right)$.

CONCLUSION: Sensory processing abilities of children with cerebral palsy were related with gross motor and fine motor capabilities. Also gross motor and fine motor capabilities are as higher, the sensory processing skill was well of cerebral palsy.

Key Words: Cerebral Palsy, Fine motor, Gross Motor, Sensory processing

\section{Introduction}

Cerebral palsy $(\mathrm{CP})$ is a permanent disability in the development of movement and posture caused by brain injury during the immature period of brain development (Campbell, 1984). It is accompanied by various problems such as sensory, perception, cognition, communication, behavior and secondary muscular issues in children (Parkes et al., 2001). In particular, motor problems caused by CP affect movement and postural development. Commonly, motor function is measured in two ways: with gross motor and fine motor manipulation abilities. Gross motor function refers to body alignment and postural control against gravity in a given context. Fine motor manipulation function is 
an index that assesses the harmony of hand and upper limb function when a child performs functional activities in daily living (Hutton and Pharoah, 2006). Because the main problem in $\mathrm{CP}$ is motor disability based on the impairment of the central nervous system, most rehabilitation interventions are focused on gross and fine motor skills (Anttila et al., 2008; Carlberg and Hadders-Algra, 2005). However, according to previous studies, children with $\mathrm{CP}$ have sensory processing issues as well as motor problems, which lead to severe developmental disability (Ahn et al., 2004; Choi et al., 2013). CP sufferers with sensory modulation problems, poor sensory registration and sensory discrimination deficits show delay issues regarding level of arousal, attention, motivation, behavioral organization, and action planning, which also affects motor functions (Ayres and Tickle, 1980; Beckung and Hagberg, 2002). About $90 \%$ of children with CP present with sensory dysfunction such as tactile and proprioceptive deficits (Cooper et al., 1995). The impaired central nervous system in $\mathrm{CP}$ produces not only abnormal muscle tone but also sensory disturbances (Cooper et al., 1995).

The main neuronal system governing sensory processing in the brain is the pyramidal tract, which connects the cerebellum, basal ganglia, and thalamus (Bleyenheuft and Gorden, 2013). The main function of the pyramidal tract is to accommodate and select sensory input from the environment. From this perspective, CP involves a deficit of the central nervous system that causes both sensory processing and motor problems (Gordon and Duff, 1999; Hosseini et al., 2015). CP limits the variety of experience that passes through sensory input because it causes asymmetrical posture, abnormal movement, and loss of postural control. These restrictions build up an improper proprioceptive sense and further incorrect movement feedback. These outcomes limit the motor planning and learning of children with cerebral palsy (McIntosh et al., 1999).

Thus, sensory processing skills and motor skills are relatively important for functional performance in daily tasks and participation (Polatajko et al., 1991). Therefore, this study investigated the difference and relationship between sensory processing abilities and gross and fine motor capabilities of children with cerebral palsy. Also, there is to identify the related factors affecting on sensory processing ability of $\mathrm{CP}$.

\section{Methods}

\section{Participants}

This study was conducted with 104 children with CP, who were receiving physical and occupational therapy from 4 pediatric rehabilitation centers in Seoul, South Korea. All children's their caregivers gave informed consent to participate in the study in accordance with the ethical principles of the Declaration of Helsinki (1975, revised 1983). The inclusion criteria were children with $\mathrm{CP}$ who were from 7 to 10 years old. Children with $\mathrm{CP}$ with other diagnoses such as intellectual disability were excluded. The mean age of the children was 8.69 years (range: 7-10 years). The mean number of weeks of pregnancy for their mothers was 39.59 weeks (range: $37-42$ weeks) and the mean birth weight was $3.4 \mathrm{~kg}$ (range: $2.8-3.8 \mathrm{~kg}$ ) (Table 1).

\section{Measurement tools}

The Short Sensory Profile (SSP) was used to measure children's sensory processing ability. The SSP was developed by Dunn (1999), and this study used the Korean version of the SSP (Dunn, 1999). The items measured were Tactile sensitivity, Taste/Smell sensitivity, Movement sensitivity, Under-responsive/Seeks sensations, Auditory filtering, Low energy/Weak, and Visual/Auditory sensation (McIntosh et al., 1999). These items include functional behavior in daily activities that are symptoms of sensory processing disorders. For example, some sample items are as follows: Tactile sensitivity - Does not like washing face 
Table 1. General characteristics of all children with CP

$(\mathrm{N}=104)$

\begin{tabular}{|c|c|c|c|}
\hline Variables & & Mean \pm SD [Range] & Frequency (\%) \\
\hline Age (year) & & $8.69 \pm 1.44[7-10]$ & \\
\hline \multirow[t]{2}{*}{ Sex } & Boys & & $56(53.80)$ \\
\hline & Girls & & $48(46.20)$ \\
\hline Pregnancy weeks & & $39.59 \pm 1.14[37-42]$ & \\
\hline Weight at birth $(\mathrm{kg})$ & & $3.40 \pm .25[2.81-3.80]$ & \\
\hline \multirow{3}{*}{ SSP Level } & Normal & & $32(30.80)$ \\
\hline & Probable difference & & $36(34.60)$ \\
\hline & Definite difference & & $36(34.60)$ \\
\hline \multirow[t]{5}{*}{ GMFCS Level } & I & & $2(1.90)$ \\
\hline & II & & $10(9.60)$ \\
\hline & III & & $28(26.90)$ \\
\hline & IV & & $34(32.70)$ \\
\hline & V & & $30(28.80)$ \\
\hline \multirow[t]{5}{*}{ MACS Level } & I & & $4(3.80)$ \\
\hline & II & & $24(23.10)$ \\
\hline & III & & $18(17.30)$ \\
\hline & IV & & $36(34.60)$ \\
\hline & V & & $22(21.20)$ \\
\hline
\end{tabular}

SD: standard deviation; SSP: short sensory profile; GMFCS: gross motor function classification system; MACS: manual ability classification system

or avoids going barefoot in sand or grass; Taste/Smell sensitivity-Avoids specific tastes or smells in routine foods, does not eat foods of specific texture or temperature; Movement sensitivity - Dislikes activities where head is upside down; Under-responsive/Seeks sensations - Seeks to make noise for noise's sake, leaves clothing twisted on body; Auditory filtering-Is distracted or has trouble functioning if there is a lot of noise around; Low energy/ Weak-Seems to have weak muscles; Visual/Auditory sensitivity - Responds negatively to unexpected loud noises. Each item is measured on a five-point Likert scale. A total score of 155 to 190 points is normal, 142 to 154 points is a probable difference, and 38 to 141 points is a definite difference in sensory processing (Dunn, 1999; Lesný et al., 1993). The normal level corresponds to typical sensory processing abilities, while the probable difference and definite difference levels correspond to atypical sensory processing abilities.

The gross motor skills of children were measured using the Gross Motor Function Classification System (GMFCS). The GMFCS classifies a child's movement ability into five levels: level I is walks without restrictions; level II is walks without restrictions, but with limitations walking outdoors and in the community; level III is walks with assistive mobility devices, but with limitations walking outdoors and in community; level IV is self-mobility with limitation; and level $\mathrm{V}$ is self-mobility that is severely limited, even with the use of assistive technology (Gunel et al., 2009; Morris and Bartlett, 2004). The children's fine motor skill was measured using the Manual Ability Classification System (MACS), which classifies the child's ability to handle objects into five levels: level I is handles objects easily and successfully; level II is handles most objects but with somewhat reduced quality or speed; level III is handles objects with difficulty, needs to modify activities; level IV is handles a limited selection of easily managed objects in adapted situations; level $\mathrm{V}$ is does not handle objects (Öhrvall, 2011). An occupational therapist evaluated 
children's sensory processing ability through the caregiver's interview using SSP. A physical therapist and an occupational therapist classified children's gross and fine motor function according to the GMFCS and MACS, respectively.

\section{Data analysis}

To analyze data on the difference between the gross and fine motor levels on sensory processing total score, a one-way analysis of variance (ANOVA) was used and post-hoc test was applied by Scheffe's method. Spearrman's co-efficient was used to determine the relationship between sensory processing sub-items, and total gross and fine motor function of the children. Finally, stepwise multivariable regression was used to identify related factors on the total sensory processing score of all children. For this, each GMFCS and MACS level was recorded to dummy variables. Findings were considered statistically significant at $\mathrm{p}<.05$.

\section{Results}

There were significant differences in total sensory processing score according to GMFCS $(\mathrm{F}=3.25, \mathrm{p}=.01)$ or MACS level $(\mathrm{F}=4.53, \mathrm{p}<.00)$ for all participants (Table 2). Following post hoc tests, significant mean differences of sensory processing ability among GMFCS and MACS level were found as follows: GMFCS level II=III $>$ IV=V,
MACS level I=II=III $>$ IV=V (Table 3). The following significant correlations between SSP sub-items and GMFCS or MACS level of all children were found: between Tactile sensitivity and both GMFCS ( $\mathrm{r}=.06)$ and MACS $(\mathrm{r}=-.06)$; between Taste-smell sensitivity and MACS $(\mathrm{r}=-.10)$; between Movement sensitivity and both GMFCS ( $\mathrm{r}=-.12)$ and MACS ( $\mathrm{r}=-.09)$; between Under responsive/ Seek sensation and MACS ( $\mathrm{r}=-.10)$; between Auditory filtering and both GMFCS $(\mathrm{r}=-.20)$ and MACS $(\mathrm{r}=-.18)$; and between Low energy/Weak and both GMFCS ( $\mathrm{r}=-.15)$ and MACS ( $\mathrm{r}=-.13)$ (Table 4).

The results of stepwise multivariable regression were as follows. MACS level 2 ( $\mathrm{B}=16.81)$, MACS level 3 $(\mathrm{B}=17.14)$, GMFCS level 2 ( $\mathrm{B}=38.17)$, and GMFCS level $3(B=18.51)$ affected the SSP total score of all children. The explanation power of this model is given by adjusted $\mathrm{R}^{2}=.62$ (Table 5).

\section{Discussion}

Children with $\mathrm{CP}$ have functional difficulties in performance during daily living not only because of abnormal postural tone and poor postural control, but also because of sensory processing problems (Blanche et al., 1995; Ko et al., 2010). In particular, sensory processing problems affect the child's adaptability to daily activities,

Table 2. Difference of SSP total score among GMFCS and MACS levels

$(\mathrm{N}=104)$

\begin{tabular}{cccccc}
\hline \multirow{3}{*}{ GMFCS } & $\begin{array}{c}\text { Level 1 } \\
(\mathrm{n}=2)\end{array}$ & $\begin{array}{c}\text { Level 2 } \\
(\mathrm{n}=10)\end{array}$ & $\begin{array}{c}\text { Level 3 } \\
(\mathrm{n}=28)\end{array}$ & $\begin{array}{c}\text { Level 4 } \\
(\mathrm{n}=34)\end{array}$ & $\begin{array}{c}\text { Level 5 } \\
(\mathrm{n}=30)\end{array}$ \\
\cline { 2 - 6 } & Mean (SD) & Mean (SD) & Mean (SD) & Mean (SD) & Mean (SD) \\
\cline { 2 - 6 } & $175.00(3.53)$ & $174.90(2.96)$ & $160.42(8.86)$ & $125.70(15.33)$ & $124.73(17.32)$ \\
\hline \multirow{4}{*}{ MACS } & Level 1 & Level 2 & Level 3 \\
$(\mathrm{n}=4)$ & $(\mathrm{n}=24)$ & Level 4 & $\begin{array}{c}\text { Level 5 } \\
(\mathrm{n}=22)\end{array}$ \\
\cline { 2 - 7 } & Mean (SD) & Mean (SD) & Mean (SD) & Mean (SD) & Mean (SD) \\
\cline { 2 - 7 } & $177.50(.57)$ & $165.25(2.12)$ & $154.44(9.62)$ & $124.00(14.35)$ & $122.18(18.04)$ \\
\hline
\end{tabular}

* Significant difference at $\mathrm{p}=.00$

One-way ANOVA was used to identify mean difference

SD: standard deviation; GMFCS: gross motor function classification system; MACS: manual ability classification system 
Table 3. Post-hoc test results of GMFCS and MACS at each level of SSP total score

\begin{tabular}{|c|c|c|c|c|}
\hline & I & $\overline{\mathrm{J}}$ & MD (I-J) & $\mathrm{SE}$ \\
\hline \multirow{10}{*}{ GMFCS } & I & II & .60 & 9.99 \\
\hline & & III & 15.07 & 9.44 \\
\hline & & IV & $49.79 *$ & 9.38 \\
\hline & & V & $50.76^{*}$ & 9.42 \\
\hline & II & III & 14.47 & 4.75 \\
\hline & & IV & $49.19 *$ & 4.64 \\
\hline & & V & $50.16^{*}$ & 4.71 \\
\hline & III & IV & $34.72 *$ & 3.29 \\
\hline & & V & $35.69 *$ & 3.39 \\
\hline & IV & V & .97 & 4.60 \\
\hline \multirow{10}{*}{ MACS } & I & II & 12.25 & 6.96 \\
\hline & & III & $23.05^{*}$ & 7.13 \\
\hline & & IV & $53.50 *$ & 6.80 \\
\hline & & V & $55.31 *$ & 7.01 \\
\hline & II & III & 10.80 & 4.02 \\
\hline & & IV & $41.25^{*}$ & 3.40 \\
\hline & & V & $43.06^{*}$ & 3.80 \\
\hline & III & IV & $30.44^{*}$ & 3.72 \\
\hline & & V & $32.26^{*}$ & 4.10 \\
\hline & IV & $\mathrm{V}$ & 1.81 & 3.49 \\
\hline
\end{tabular}

*Post hoc test used Scheffe method and significant mean difference at $\mathrm{p}<.05$

MD: mean difference; SE: standard error

GMFCS: gross motor function classification system; MACS: manual ability classification system

Table 4. Correlations between SSP sub-items, GMFCS and MACS of total CP

$(\mathrm{N}=104)$

\begin{tabular}{llll}
\hline & & GMFCS & MACS \\
\hline & Tactile sensitivity & $.06^{* *}$ & $-.06^{* *}$ \\
& Taste/Smell sensitivity & -.01 & $-.10^{* *}$ \\
MSP sub-items & Movement sensitivity & $-.12^{* *}$ & $-.09^{* *}$ \\
& Under responsive/Seek sensation & .01 & $-.10^{* *}$ \\
& Auditory filtering & $-.20^{* *}$ & $-.18^{* *}$ \\
& Low energy/Weak & $-.15^{* *}$ & $-.13^{* *}$ \\
& Visual/Auditory sensitivity & .00 & .01 \\
\hline
\end{tabular}

**significant correlations at .01 level

Spearman's rho was used to identify the correlations

SSP: short sensory profile; GMFCS: gross motor function classification system; MACS: manual ability classification system

Table 5. Stepwise multivariable regression model for prediction of SSP total score

$(\mathrm{N}=104)$

\begin{tabular}{|c|c|c|c|c|c|c|}
\hline Predictor & Coefficient (B) & SE & $\beta$ & $\mathrm{t}$ & $\mathrm{R}^{2}$ & Adjusted $\mathrm{R}^{2}$ \\
\hline MACS level $2^{\#}$ & 16.81 & 5.95 & .29 & $2.82 *$ & \multirow{4}{*}{$.64 *$} & \multirow{4}{*}{$.62 *$} \\
\hline MACS level $3^{\#}$ & 17.14 & 5.35 & .27 & $3.20 *$ & & \\
\hline GMFCS level $2^{\S}$ & 38.17 & 6.24 & .47 & $6.11 *$ & & \\
\hline GMFCS level $3^{\S}$ & 18.51 & 5.71 & .34 & $3.24 *$ & & \\
\hline
\end{tabular}

SE: standard error

* significant level $\mathrm{p}<.05$

\# reference level of MACS variable is level 1

$\S$ reference level of GMFCS variable is level 1

Expected variables by stepwise selection were age, sex, weight, pregnancy weeks, MACS level 4, 5 and GMFCS level 4, 5 . 
mood, emotion, and motor function (Ayres and Tickle, 1980; Papavasiliou, 2009). According to previous studies sensory processing problems in children induce developmental issues such as low or high postural tone, deficits of balance and motor coordination, unstable posture, and/or clumsy movement. Therefore, in CP, symptoms of sensory integration disorders are more prevalent (Ayres, 1980; Lee and Song, 2010).

In this study, there were significant differences between gross and fine motor skill levels and sensory processing levels in children. The results of post hoc testing showed that GMFCS levels II and III showed similar in SSP total scores, and GMFCS levels IV and V showed similar in SSP total scores. While, GMFCS levels II and V showed the most significantly mean difference in SSP total score. This means that sensory processing abilities are different for children with severe limitations in self-mobility versus those capable of independent walking without restrictions. The SSP total scores were similar at levels I, II and III compared with IV and V in MACS. The SSP total scores showed the most significant mean differences between levels I and V in MACS. These results confirmed that the sensory processing abilities of children with $\mathrm{CP}$ differ between good and poor in the manual ability of the upper extremity and hands.

This study identified significant correlations between sub-items of SSP and both GMFCS and MACS in children with $\mathrm{CP}$. According to the finding, the SSP sub-items Tactile sensitivity, Movement sensitivity, Auditory filtering and Low energy/Weak were significantly weak correlated with both GMFCS and MACS. In previous studies, about $40-70 \%$ of children with $\mathrm{CP}$ who had sensory problems exhibited sensory discrimination disorder (Lesný et al., 1993). Children with CP have primary sensory disorders such as tactile or proprioceptive discrimination (Nashner et al., 1983; Wingert et al., 2008). This problem mainly affects the fine motor manipulation skill in CP (Levitt, 2013). Even though it is a weak correlation, this study showed similar results: tactile processing problems were significantly correlated with gross motor, upper extremity and manual functions. Also, the results of this study showed that gross and fine motor levels were weak correlated with the SSP sub-items Movement sensitivity, Auditory filtering and Low energy/Weak. These items are all influenced by the vestibular system. According to Hosseini et al. (2015), children with $\mathrm{CP}$ with sensory processing problems showed insecurity to antigravity. The ability to integrate gravity is essential in the normal developmental process. Various studies have shown that children's vestibular systems are important for postural control and gross motor performance (Campbell, 1984). In particular, the vestibular sense is related to balance and motor coordination and is a key factor for gross motor ability and postural control (Østensjø et al., 2004). The result of stepwise multivariable regression analysis showed that MACS and GMFCS variables affected the SSP total score: as MACS level increased and GMFCS level increased, SSP total score also increased. The model's estimation regression equation was as follows: SSP total score $=124.00+(16.81 \times$ MACS level 2$)+(17.14 \times$ MACS level 3) $+(38.17 \times$ GMFCS level 2$)+(18.51 \times$ GMFCS level 3). The explanation power of this model was reliable, at $62.70 \%$. These results mean that children with $\mathrm{CP}$ whose gross motor and manual functional abilities in daily activities are better; e.g., at level 2 or level 3, their sensory processing abilities are better than those with MACS and GMFCS levels of 4 or 5 .

\section{Conclusion}

This study was performed to investigate the difference and relationship between sensory processing abilities, gross motor and fine motor capabilities in children with cerebral palsy. The results showed that Tactile sensitivity, Movement sensitivity, Auditory filtering and Low energy/Weak were weak linear correlated with both GMFCS and MACS of 
CP. Also, the result showed that the higher gross and fine motor capabilities, the better sensory processing abilities. The result has clinical meaning as it identifies the relationships between the sensory processing ability of children with $\mathrm{CP}$ and their GMFCS and MACS level. As with all results, this study has some limitations. This study used only the short form sensory profile, and future studies should involve a greater number of children and should use the long form sensory profile. The next step in the research should to be to compare sensory processing ability with gross and fine motor abilities among the various types of $\mathrm{CP}$.

\section{Acknowledgements}

This research was supported by Baekseok University research fund.

\section{References}

Ahn RR, Miller LJ, Milberger S, et al. Prevalence of parents' perceptions of sensory processing disorders among kindergarten children. Am J Occup Ther. 2004;58(3): 287-93.

Anttila H, Autti-Ramo I, Suoranta J, et al. Effectiveness of physical therapy interventions for children with cerebral palsy: a systematic review. BMC Pediatr. 2008:8:14.

Ayres AJ, Tickle LS. Hyper-responsivity to touch and vestibular stimuli as a predictor of positive response to sensory integration procedures by autistic children. Am J Occup Ther. 1980;34(6):375-81.

Beckung E, Hagberg. Neuroimpairments, activity limitations, and participation restrictions in children with cerebral palsy. Dev Med Child Neurol. 2002;44(5):309-16.

Blanche EI, Botticelli TM, Hallway MK. Combining neurodevelopmental treatment and sensory integration principles: an approach to pediatric therapy. USA. Therapy Skill Builders. 1995.

Bleyenheuft Y, Gordon AM. Precision grip control, sensory impairments and their interactions in children with hemiplegic cerebral palsy: a systematic review. Res Dev Disabil. 2013;34(9):3014-28.

Campbell SK. Pediatric neurologic physical therapy $\left(5^{\text {th }}\right.$ ed). USA. Churchill Livingstone. 1984.

Carlberg EB, Hadders-Algra M. Postural dysfunction in children with cerebral palsy: some implications for therapeutic guidance. Neural Plast. 2005;12(2-3):221-8.

Choi YC, Park SJ, Lee MH, et al. The effects of trunk muscle strengthening exercise on balance performance of sitting posture and upper extremity function of children with diplegic cerebral palsy. J Korean Soc Phys Med. 2013;8(1):117-25.

Cooper J, Majnemer A, Rosenblatt B, et al. The determination of sensory deficits in children with hemiplegic cerebral palsy. J Child Neurol. 1995;10(4):300-9.

Dunn W. Sensory Profile: User's Manual. USA, TX: Psychological Corporation. 1999.

Gordon AM, Duff SV. Relation between clinical measures and fine manipulative control in children with hemiplegic cerebral palsy. Dev Med Child Neurol. 1999;41(9):586-91.

Gunel MK, Mutlu A, Tarsuslu T, et al. Relationship among the Manual Ability Classification System (MACS), the Gross Motor Function Classification System (GMFCS), and the functional status (WeeFIM) in children with spastic cerebral palsy. Eur J Pediatr. 2009;168(4):477-85.

Hosseini SA, Ghoochani BZ, Talebian S, et al. Investigating the effects of vestibular stimulation on balance performance in children with cerebral palsy-A Randomized Clinical Trial study. JRSR. 2015;2(2):41-6.

Hutton JL, Pharoah PO. Life expectancy in severe cerebral palsy. Arch Dis Child. 2006;91:254-8.

Ko MS, Chung JH, Jeon HS. Correlation between pediatric 
balance scale (PBS) and gross motor function measurement (GMFM) scores in children with cerebral palsy. J Korean Soc Phys Med. 2010;5(2):281-8.

Lee EJ, Song JM. Change in the gross motor function, self-esteem and social ability of children with spastic diplegia from group exercise: case study. J Korean Soc Phys Med. 2010;5(4):645-54.

Lesný I, StehliAk A, TomásCek J, et al. Sensory disorders in cerebral palsy: two-point discrimination. Dev Med Child Neurol. 1993;35:402-5.

Levitt S. Treatment of cerebral palsy and motor delay. USA. John Wiley \& Sons. 2013.

McIntosh D, Miller L, Shyu V, et al. Overview of the short sensory profile (SSP). The sensory profile: Examiner's manual. 1999.

Morris C, Bartlett D. Gross motor function classification system: impact and utility. Dev Med Child Neurol. 2004; 46(1):60-5.

Nashner L, Shumway-Cook A, Marin O. Stance posture control in select groups of children with cerebral palsy: deficits in sensory organization and muscular coordination. Exp Brain Res. 1983;49(3):393-409.
Öhrvall A. Manual Ability Classification System (MACS): development, evaluation and applicability. Sweden, Karolinska institutet. 2011.

Østensjø S, Carlberg EB, Vøllestad NK. Motor impairments in young children with cerebral palsy: relationship to gross motor function and everyday activities. Dev Med Child Neurol. 2004;46(9):580-9.

Papavasiliou AS. Management of motor problems in cerebral palsy: a critical update for the clinician. Eur J Paediatr Neurol. 2009;13(5):387-96.

Parkes J, Dolk H, Hill N, et al. Cerebral palsy in Northern Ireland: 1981-93. Paediatr Perinat Epidemiol. 2001; 15(3):278-86.

Polatajko HJ, Law M, Miller J, et al. The effect of a sensory integration program on academic achievement, motor performance, and self-esteem in children identified as learning disabled: Results of a clinical trial. OTJR. 1991;11(3):155-76.

Wingert JR, Burton H, Sinclair RJ, et al. Tactile sensory abilities in cerebral palsy: deficits in roughness and object discrimination. Dev Med Child Neurol. 2008;50(11): 832-8. 